\title{
The Global AIDS Situation as of November 1987*
}

The numbers of reported cases of AIDS and countries reporting AIDS have continued to increase dramatically. As of 11 November 1987, 64,488 AIDS cases have been officially reported to the World Health Organization (WHO) from 127 countries. However, this number represents only a fraction of the total cases of AIDS to date, which are estimated to be between 100,000 and 150,000 . WHO estimates that between 5 and 10 million persons may be currently infected with human immunodeficiency virus, or HIV - the virus which causes AIDS. By 1991, WHO estimates that at least one million new cases of AIDS could develop in people already infected with HIV.

AIDS has been reported from every part of the world. The largest number of cases, 43,533, have been reported in the United States, where the disease was first recognized in 1981. In 40 other countries in the Americas, a total of 6,259 cases have been reported. In the Americas, Europe, and Australia, most AIDS cases occur among young, 20-49 years-old homosexual or bisexual men and intravenous drug-users. However, the estimate of the proportion of cases of AIDS acquired through heterosexual contact has increased from $1 \%$ to approximately $4 \%$. The United States Public Health Service estimates that, by 1991, 270,000 cases of AIDS will have occurred in the United States of America alone-nearly five times the total number of cases reported world-wide so far.

In Europe, where 27 countries have reported 7,512 AIDS cases, most countries are now considered to be facing an epidemic. WHO estimates that 500,000 to one million persons in Europe are infected with the AIDS virus. Highest per caput cases of AIDS are found in Switzerland, Denmark, France, and Belgium. WHO estimates that there will be 25,000 new cases of AIDS in Europe by the end of 1988.

In Africa, the number of countries reporting AIDS to WHO has increased substantially in the past year. As of 11 November, 37 African nations had reported 6,298 cases of AIDS. Major factors of HIV-spread in Africa are heterosexual transmission, transfusions with unscreened blood, use of unsterilized needles or syringes, and mother-to-child transmission. The last is a significant source of infection, especially in areas where 5-10\% of pregnant women have been recorded as HIV-seropositive.

In Asia, 18 countries have reported 208 cases of AIDS. Many of those cases are linked to persons who have been in areas where AIDS is more prevalent than in the countries concerned. Oceania (including Australia and New Zealand) has reported 678 cases.

Despite considerable research, a vaccine may be farther away than was thought a.year ago. In addition, a cure for AIDS is still lacking. In the absence of a vaccine, or effective, curative treatment, education and information on how to avoid AIDS remains the key to controlling its spread.

Control Programme on AIDS World Health Organization

Avenue Appia 20

1211 Geneva 27

Switzerland.

\footnotetext{
* See also the more detailed 'AIDS-An International Perspective', by Drs Fakhry Assaad \& Jonathan M. Mann, published in our
} Summer issue of this year (Environmental Conservation, Vol. 14, No. 2, pp. 174-6, 1987). - Ed.

\section{The Virginia Environmental Endowment*}

The Virginia Environmental Endowment(VEE), formed ten years ago in the aftermath of the Kepone insecticide pollution of the James River in Virginia, is an object lesson in how to turn pollution events into a positive force for environmental protection.

Since its founding in 1977 with an $\$ 8$ millions contribution from Allied Chemical Corporation as part of the settlement of the United States Government's case against Allied, VEE has spent approximately $\$ 8$ millions and still has assets of $\$ 18$ millions to continue its work. A further settlement-of $\$ 1$ million from the FMC Corporation in 1981 as a result of a guilty plea agreement over the discharge of carbon tetrachloride into the Kanawha River of the neighbouring State of West Virginia - has enabled VEE to expand its work beyond the borders of the State of Virginia.

As a result of grants made by VEE, new institutions have been created, new research on the effects of toxic substances on human health and the environment has been conducted, and numerous educational, legal, and commu-

* Indicating impressive advances since we published an account of VEE in 1983 (Environmental Conservation, Vol. 10, No 3, pp. 166-7). - Ed. nity-based, activities have taken place. The following is an abbreviated list of some of these accomplishments:

* The Institute for Environmental Negotiation was created at the University of Virginia. The Institute is a mediation centre for revolving complex environmental disputes that has successfully mediated a variety of situations over the last five years.

* The Division of Clinical Toxicology and Environmental Medicine was established at Virginia Commonwealth University's Medical College of Virginia. This institution performs advanced medical research on toxics, educates physicians, and treats patients with disorders of toxic origin.

* The Water Education Institute was set up at Virginia Polytechnic Institute and State University, to provide intensive and extensive educational programmes on water resource management.

* The Environment Defense Fund was able to establish a Virginia office to provide legal and scientific expertise to Virginians.

* The Virginia Toxics Roundtable, a group of chemical industry and environmental leaders, was established, and played a major role in developing Virginia's new hazardous-waste facility siting law. 